\title{
Index Revision, House Price Risk, and the Market for House Price Derivatives
}

\author{
Yongheng Deng • John M. Quigley
}

Published online: 11 April 2008

(C) Springer Science + Business Media, LLC 2008

\begin{abstract}
It is widely recognized that options and futures markets for housing can reduce and manage the risks inherent in consumers' large investments in housing equity. The integrity of such markets depends, however, upon the use of transparent and replicable benchmarks for house prices and settlement values. In the USA, a series of state and metropolitan indexes have been produced by a government agency (the US Office of Housing Enterprise Oversight, OFHEO), and they have been widely disseminated for over a decade. By construction, the entire historical path of each of these indexes is, in principle, subject to revision quarterly, that is, every time the index is recalculated and data are published. This paper provides the first analysis of the magnitude and bias of these revisions, and it analyzes their systematic effects on the settlement prices in housing options markets. The paper considers the implications of these magnitudes for the development of risk-reducing futures markets.
\end{abstract}

Keywords Repeat sales index $\cdot$ Index revision $\cdot$ House price risk .

House price derivative

JEL Classification $\mathrm{G} 11 \cdot \mathrm{R} 21 \cdot \mathrm{G} 13$

Earlier versions of this paper were presented at the Cambridge-UNC Symposium on Risk Management, Cascais, Portugal, June 2007, at the USC Lusk Center Research Seminar in September 2007, at the ASSA Meetings in New Orleans in January 2008, and at the UC Irvine Symposium on Urban Research, Laguna Beach, CA February 2008. The paper benefited from the comments of Richard Buttimer, David Feldman, and Audrey Pavlov. We are grateful to Andrew Leventis for providing us with previous releases of the OFHEO price indexes from the agency's archives and to Peng Fei and Minye Zhang for expert research assistance.

\section{Y. Deng $(\bowtie)$}

University of Southern California, Los Angeles, CA, USA

e-mail: ydeng@usc.edu

J. M. Quigley

University of California, Berkeley, CA, USA

e-mail: quigley@econ.berkeley.edu 


\section{Introduction}

Proposals to develop institutions which would permit homeowners to hedge their unbalanced investment portfolios were first proposed almost 15 years ago (see Case et al. 1993), and there is now convincing evidence that households could be made much better off by a functioning market in house price derivatives. Detailed empirical evidence from Sweden (Englund et al. 2002) and from the U.K. (Iacoviello and Ortalo-Magné 2003) is consistent with large gains through risk management; cruder analyses based upon data from the Global Financial Database suggest that large gains could accrue to homeowners in many other European countries as well (Quigley 2006).

This quite recent research also suggests that there are social as well as private gains to mobilizing this market. These concerns have motivated one public demonstration currently underway in the USA, supported by government funds (see Goetzmann et al. 2003). These social concerns also provide an additional rationale for contemporaneous efforts by the private sector to develop a functioning market for house price derivatives. In the USA, these latter efforts have been sponsored by the Chicago Mercantile Exchange (CME) which has sought to develop "alternative non-traditional investment products to enable customers to better diversify and manage their risks." (CME 2007a, b, p2). Among the products under development are CME Economic Derivatives, CME Weather Derivatives, and CME Housing Futures and Options.

This latter program currently seeks to develop a market for housing derivatives in ten USA metropolitan areas. Presumably, the lessons learned in this initial program will inform choices about a larger national system of trading in housing futures.

The key to trading in housing futures is the development of reliable and replicable indexes of housing prices, differentiated according to appropriate geographical regions. Although many choices are possible, current institutions for hedging in the USA will almost certainly use some version of a repeat sales (RS) price index (see Bailey et al. 1963). The methodology for producing such an index from a sample of paired sales of dwellings is well known, and the methodology can be implemented across housing markets without resort to detailed measurement of the characteristics of the individual houses which are bought and sold.

One attribute inherent in the RS methodology is that the house price indexes which are so derived are subject to revision as new information is revealed. Additional information on paired sales is used, not only to estimate the contemporaneous value of the index, but also to revise the entire history of index values over time. This paper considers the practical importance of this feature, index "revision," in the development of the market for risk-reducing derivatives. In Section II below, we lay out the problem and discuss previous work investigating its practical importance. Previous work is quite limited and is based entirely upon the ad hoc analyses of particular bodies of specialized data on housing prices.

However, for the USA at least, there exists one consistent body of government data on house prices gathered and published for Census Regions, states, and metropolitan areas. The Office of Federal Housing Enterprise Oversight (OFHEO), established in 1992, has assembled and estimated repeat sales price indexes for a large number of US metropolitan areas (see Calhoun 1996). This set of price indexes 
was first published in March 1996, and it currently provides quarterly estimates of housing prices for 381 different metropolitan housing markets. These indexes are widely used in the real estate industry and in academic research as well.

Importantly, by comparing the historical data on house prices, that is, the paths of index values released by OFHEO at two different points in time, it is possible to identify the magnitude and importance of the revisions to these indexes as estimates of market prices - and as instruments for the settlement of options and futures contracts. ${ }^{1}$ This analysis is presented in Section III. Section IV is a brief conclusion.

\section{Repeat Sales Indexes}

The enormous advantage of the RS estimator of housing prices is its parsimonious use of information. The value, $V$, or "selling price" of a house is simply price, $P$, times quantity, $Q$ :

$$
\log V=\log P+\log Q .
$$

The unit price $P$ of housing at time $t$ is unobserved, but the quantity of housing services emitted by a dwelling $i$ can be measured, at least in principle, by a vector of characteristics, $X$ :

$$
\log V_{i t}=X_{i t} \beta_{t}+d_{i t} \delta_{t}+\varepsilon_{i t} .
$$

In Eq. $2, d$ is a dummy variable with a value of one if dwelling $i$ was sold in period $t$, $\varepsilon$ is an error term, and $\beta$ and $\delta$ are parameters. If dwelling $i$ was sold at times $t$ and $T$, then

$$
\log V_{i t}-\log V_{i T}=X_{i t} \beta_{t}-X_{i T} \beta_{T}+d_{i t} \delta_{t}-d_{i T} \delta_{T}+\varepsilon_{i t}-\varepsilon_{i T} .
$$

If it is assumed that housing attributes are unchanged between $t$ and $T, X_{i t}=X_{i T}$, and that the implicit prices of these attributes are also unchanged, $\beta_{t}=\beta_{T}$, then the price relationship is simply

$$
\log \left(V_{i t} / V_{i T}\right)=D_{i t T} \delta+e_{i t T} .
$$

Here $D$ is a matrix of dummy variables taking a value of minus 1 at the time of the first of the paired sales, $t$, plus 1 at the time of the second of the paired sales, $T$, and zero otherwise. In Eq. 4, $e$ is an error term, and the vector $\delta$ is the price index for housing. Further assumptions about the error terms associated with individual house sales, $\varepsilon$, for example, a random walk in house prices (i.e., Case and Shiller 1989), determines the distribution of $e$.

Under these conditions, the price index for housing can be determined directly from Eq. 4. Knowledge of the selling prices of a sample of houses traded at two

\footnotetext{
${ }^{1}$ OFHEO releases a new series of historical housing prices for each covered MSA quarterly. At the time a newly estimated series is released on the OFHEO website, the previous series is removed from public view. Andrew Leventis of OFHEO was able to obtain and transmit to us the complete historical file of house price estimates released in 2001Q1 for comparison with the most current historical series released, estimating house price series as of 2007Q1.
} 
points in time, and the dates of these sales, is sufficient to estimate the price index. Distributional assumptions about $\varepsilon$ determine the efficient estimator for the index values.

Understandably, considerable interest has been focused on the implications of the assumptions of constant implicit prices and unchanged housing characteristics. Analyses based upon detailed micro data facilitate comparisons in indexes between repeat sales price techniques and other forms of hedonic price estimation. These results suggest that the assumptions of constant hedonic prices and unchanged housing attributes are consistently violated (see, for example, Clapham et al. 2006 for an extensive analysis and comparison).

However, detailed hedonic characteristics of dwellings are seldom available, certainly not in sufficiently large samples so as to support a derivatives market (but there are exceptions in some countries which have adopted national systems of property taxation and hedonic assessment methods, see Englund 2003; Quigley 2006). In most cases, a practical market for housing futures must be based on a pricing algorithm that resembles some version of that described in Eq. 4.

Under this standard, however, the addition of new information about contemporaneous paired sales inexorably leads to changes in the estimates of the values of the price index in all previous periods. These revisions are potentially important, and they may affect the integrity of a market in which trades are settled with reference to the calculated values of these indexes.

Under the rules currently in force for trading on the CME Housing Futures and Options Exchange, all trades are settled on the initial announcement of housing prices. One "frequently asked question" in the CME's on-line description of the market is: "Can the index values be changed after the initial announcement? Does this affect settlement?" The published rules are unequivocal:

"The index values can be changed after the initial announcement but the final settlement DOES NOT change... Market positions will be decided based on the initial index announcement. Revisions are for informational purposes only" (CME 2007b, p1; emphasis in the original).

If index revisions are "large," the settlement rule becomes arbitrary, and the efficiency advantages of the market are problematic. Similarly, if the revisions to initially announced index values are systematically "upwards" or "downwards," this affects the returns to index investment in a systematic way. Under any of these conditions - "large" or "systematic" revisions - a derivatives market becomes less attractive to consumers and investors, and it provides less in terms of social benefit.

Little is known about the magnitude of house price revisions or the systematic bias of these revisions. Two studies have used detailed, but quite specialized, micro data to investigate this issue. Clapp and Giaccotto (1999) analyzed micro data reporting the sales of single family housing in Fairfax County, Virginia and also in four postal codes (five-digit zip codes) in Los Angeles to analyze the effect of revision on price index values. In each of these samples, the authors found that index revisions are large, insensitive to sample size, and systematically "downwards." Clapham et al. (2006) analyzed a very large sample of single transactions $(137,000)$ and repeat sales $(75,000)$ of single family housing in Stockholm over a 19-year period. This analysis suggested that price indexes based on hedonic characteristics 
were more stable than those based upon repeat sales. More importantly for the development of a market for derivatives, index revision in the light of subsequent information was found to be systematic and to be "downwards." Later revisions to initially published indexes were more likely to reduce estimated house values than they were to increase estimated values.

Some information is available on the properties of publicly available repeat sales indexes under revision. An early paper by Abraham and Schauman (1991) compared the original "Freddie Mac Weighted Repeat Sales Index" with other indexes at the level of the US Census Region. The authors included a detailed discussion of the problems encountered when data on additional sales become available, but they did not evaluate the importance of this problem empirically.

Butler et al. (2005) analyzed the revision pattern for Freddie Mac's Conventional Mortgage Home Price Index (CMHPI) at the level of Census regions, finding a substantial and systematic bias in the revisions of the index related to the timing of the incorporation of new information throughout the year. ${ }^{2}$ This resulted in improvements in the administration and data collection procedures employed by Freddie Mac in support of the actual computation of the CMHPI (and the OFHEO) index.

Practically speaking, in the USA a broad housing futures market would necessarily be based upon the repeat sales indexes published by OFHEO or by some other large organization. The OFHEO effort has been undertaken continuously since 1996. The index is currently available for each of the 381 metropolitan areas defined for the USA, and for each state and Census Region as well. These indexes are updated and released quarterly, and current values can be downloaded directly from the OFHEO website. Newly released data are widely reported in the popular press and in the business press. Despite the fact that the index has been maintained for more than a decade and that it is widely used for commercial and academic purposes, no information is available on the properties of the index as it has been routinely revised. ${ }^{3}$

The remainder of this paper provides some assessment of the OFHEO index as it has been revised to incorporate additional information on the sales of single family housing.

\section{Revisions to the OFHEO Quarterly House Price Indexes}

We were able to obtain a complete set of the OFHEO housing price indexes in their most recent release, October 2007, reporting historical house price data through the first quarter of 2007 (2007Q1). We were also able to obtain the complete set of OFHEO house price indexes as they were released in mid 2001, updated through

\footnotetext{
${ }^{2}$ Indeed, the method of incorporating new information into the CMHPI and the OFHEO Index was changed as a result of the Butler, et al, study.

${ }^{3}$ It should also be noted that no information at all is available for indexes produced by private firms. For example, little information (and no historical information) is available about the properties of the Fiserv CSW indexes used by the CME in its pilot program. In contrast, detailed data on the procedures and estimation methods underlying the OFHEO price series are available on the agency's website.
} 
2001Q1. The 2001 data includes 23,517 valid (non-missing) estimates of housing prices over time in 329 metropolitan areas from 1975Q1 through 2001Q1. The 2007 data set is about 50\% larger; it consists of 35,692 valid estimates of housing prices over time. Both 2001Q1 and 2007Q1 house price indexes are normalized to 1995Q1, i.e., the house price indexes are set to 100 in the first quarter of 1995 for all MSAs in both files. The 2001 data are reported in four-digit MSA codes; the 2007 data uses a different five-digit MSA code. These codes are explained in detail in bulletins published by the US Office of Management and Budget (for example, the current definitions and codes are explicated in OMB Bulletin 07-01 issued on December 16, 2006).

Figure 1 is a schematic of the course of MSA housing prices between 1980 and 2007 as reported by OFHEO in October 2007. Housing prices are deflated by the overall consumer price index, and all prices are normalized to 1995Q1. The range of variation over time and across MSA is enormous.

We matched the price index data released in 2001 and 2007 for US metropolitan areas. This provides an opportunity to observe the magnitude of the revisions to price estimates in different housing markets during a 6-year interval. In Section B below, we analyze the magnitude of average revisions and the distribution of revisions by time period and geographic region. In Section $C$, we investigate the timing of revisions and their serial correlation. In Section D, we analyze the predictability of these revisions over time and across geographic regions.

Before discussing these comparisons, we report in Section A the results of matching the economic geography covered by these detailed estimates over the 6year interval.

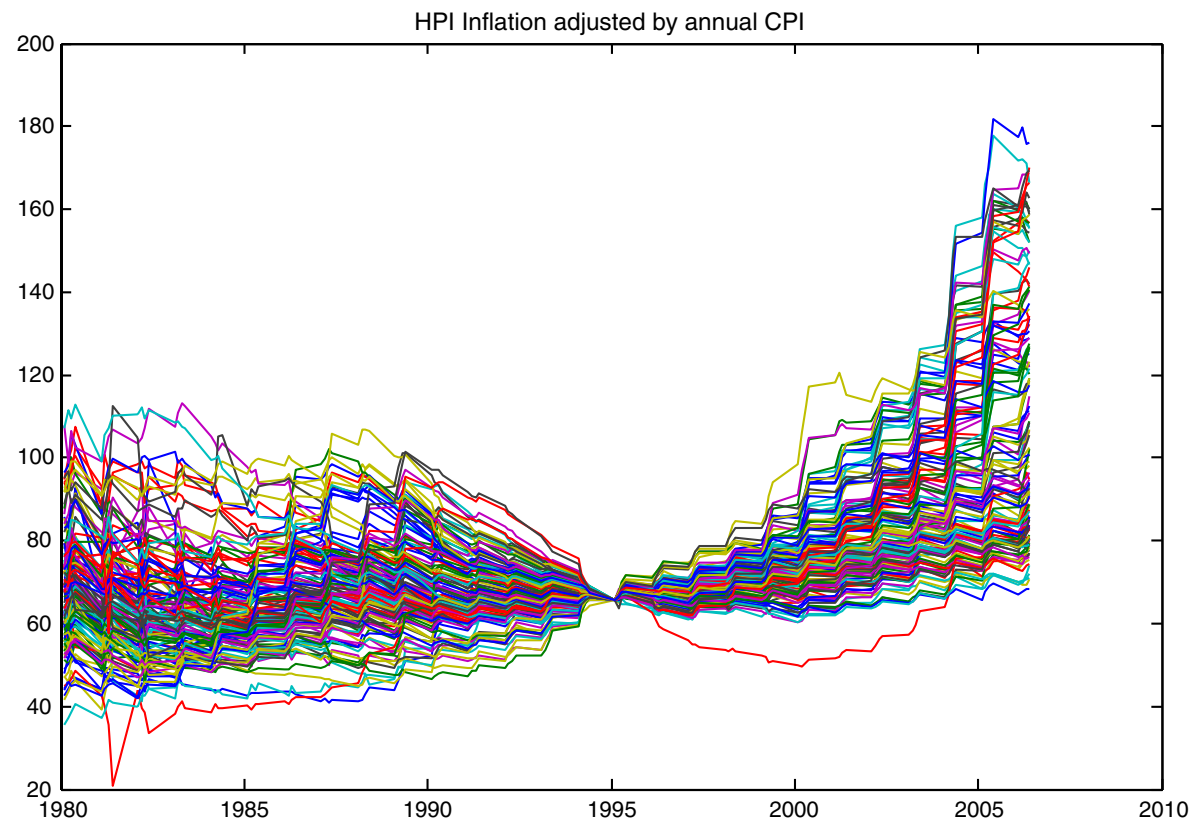

Fig. 1 Real housing prices by MSA as estimated by OFHEO, 1980-2007

를 Springer 


\section{Price Revisions and Economic Geography: Regional Definitions}

As noted above, the 2001 data were reported separately for MSAs identified by a four-digit code. There were 329 MSAs reported in 2001. The most recent set of indexes are reported for MSAs identified by a five-digit code. A total of $381 \mathrm{MSAs}$ are represented in the 2007 data. We matched these geographical regions using the OMB definitions and names which coincided with the dates of publication of the indexes.

Table 1 reports the results of matching these codes and MSA names for 2001Q1 and 2007Q1. As a result of the match, we found that 20 of the 329 MSAs whose price indexes were reported in 2001 were no longer represented in the data released for 2007. In addition, 74 of the 381 MSAs whose price indexes were reported in 2007Q1 were not found in the file released 6 years earlier. Of the remaining 309 metropolitan areas whose indexes were reported in 2001, 125 had a different name in 2007. In some cases, it appears that the definition of the housing market had changed only a little. ${ }^{4}$ In other cases, the name change signified a much larger change in economic geography. ${ }^{5}$ We also found cases in which two MSAs reported in 2001 were consolidated into one MSA reported in $2007 .{ }^{6}$ In yet other cases, a single MSA appears to have been split between 2001 and 2007-as when the DaytonSpringfield, OH MSA became the Dayton, OH MSA and the Springfield, $\mathrm{OH}$ MSA in 2007.

For the 125 MSAs that have different names in these two files, we attempted to match the geographical areas manually, In our match, we required an exact match of the names of the state and the constituent counties from the two files. We also verified the population of the constituent counties from the two files as an additional robustness check. The manual matching process allowed us to match another 54 MSAs from the two files. This yielded a total of 238 matched MSAs from the 2001 and 2007 files; 91 MSAs from 2001 file and 145 MSAs from 2007 files could not be matched, even after manual and visual inspection of the geography.

The important point to note is that for more than $47 \%$ of the metropolitan areas which were identified in 2001, the geographical definition of the regional housing market had changed in a little over 5 years. In the cases of changed boundaries, the use of the reported price indexes to settle futures contracts, entered into in 2001 for settlement in 2007, would appear to be quite problematic. This applies to the logic of using current index values, rather than to the mechanics of revising a set of index numbers in the light of additional information on paired sales revealed during the time interval. This, by itself, would seem to preclude the use of OFHEO price

\footnotetext{
${ }^{4}$ For example, the name of the Denver, CO MSA (code number 2080 in 2001) was changed to the Denver-Aurora, CO MSA (code number 19740 in 2007). Presumably, this change reflects the addition of Aurora County to the MSA which had previously included only Denver County.

${ }^{5}$ For example, when the San Francisco, CA and Oakland, CA MSAs (code numbers 7360 and 5775, respectively, in 2001) became the San Francisco-San Mateo-Redwood City, CA MSA and the OaklandFremont-Hayward, CA in 2007 (code numbers 41884 and 36084, respectively).

${ }^{6}$ For example, the Bridgeport CT MSA and the Stamford-Norwalk, CT MSA (code numbers 1160 and 8040, respectively in 2001) became the Bridgeport-Stamford-Norwalk CT MSA in 2007 (code number 14860). Similarly, the Manchester, NH MSA and the Nashua, NH MSA in 2001 (code numbers 4760 and 5350 respectively) were merged into the Manchester-Nashua, NH MSA in 2007 (code number 31700).
} 
Table 1 Geographical coverage of price index estimates in 2001 and 2007: number of metropolitan statistical areas (MSAs) in 2001 and 2007

MSA names

Number

MSAs with price indexes reported in 2001Q1

MSAs with price indexes reported in 2007Q1

MSAs with identical names in 2001Q1 and 2007Q1

Manual matching required an exact match of the names of the state and the constituent counties from the two files. We also verified the population of the constituent counties from the two files as a robustness check. Two MSAs in the 2007Q1 file result from the consolidation of MSAs reported in 2001: the Bridgeport CT MSA and the Stamford-Norwalk, CT MSA (code numbers 1160 and 8040, respectively in 2001) became the Bridgeport-Stamford-Norwalk CT MSA in 2007 (code number 14860); the Manchester, NH MSA and the Nashua, NH MSA in 2001 (code numbers 4760 and 5350, respectively) were merged into the Manchester-Nashua, NH MSA in 2007 (code number 31700). As a result, these two MSAs in 2007Q1 have been matched twice. Thus, there are 381 distinct MSAs plus two duplicate MSAs. After 184 have been exactly matched and 54 have been manually matched, there remain 145 MSAs from 2007Q1 cannot not be matched $(381+2-184-54=145)$

indexes in the settlement of futures contracts - at least unless these definitional issues were carefully addressed and adequately resolved.

\section{The Magnitude of Price Revisions}

For the 238 MSAs which covered identical geographical areas in 2001 and 2007 (184 with identical names plus 54 others matched manually), we investigate the magnitude of price revisions during the 6-year interval. Note that only nine of the 25 largest MSAs can be matched in 2001 and 2007.

Figures 2, 3, 4 and 5 summarize the distribution of index revisions. For each of these MSAs, we have an index number for each quarter after it entered the sample (1975Q1 or later) through 2001Q1 as reported in the OFHEO series released in 2001. We also have an index number for each of these same quarters, 1975Q12001Q1, as reported in the OFHEO series released in October 2007. The index numbers differ because paired sales reported after the 2001 release affect the computation of all index numbers for each metropolitan area. For each of the four figures, we report a histogram of the frequency distribution of revisions, a kernel density function estimated from the underlying frequency distribution, and a standard normal distribution with the same mean and standard deviation as the raw data.

Figure 2 summarizes the distributions of the revisions to the indexes, in percent. The figure presents the distribution of the average percentage revision across the 238 MSAs. As reported in the figure, the average revision in any metropolitan area is quite small, about $-0.125 \%$. In only about $7 \%$ of the MSAs, is the average index more than $1 \%$ larger than the average index as it was originally reported. In even a smaller fraction of the cases, the revised index is more than $1 \%$ smaller than the average originally reported. 


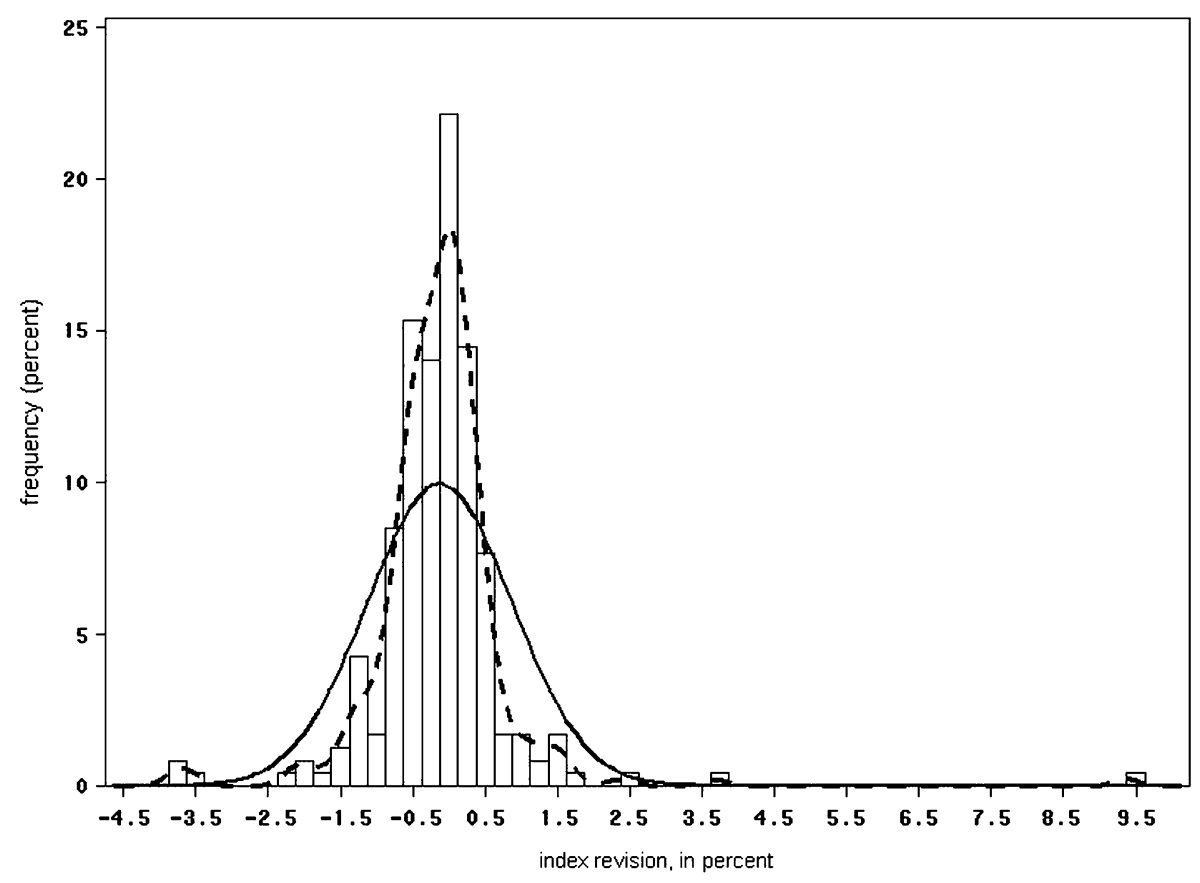

Fig. 2 Frequency distribution of quarterly revision in price index, in percent 2007Q1 versus 2001Q1 (238 MSAs)

Figure 3 reports a more meaningful comparison, the frequency distribution of the average absolute revision to the index for the 238 MSAs. As the figure indicates, more than $55 \%$ of the time, the average absolute revision is less than $0.75 \%$ after the passage of about 6 years. However, in about one quarter of the cases the revision is greater than $1.5 \%$, and in about $15 \%$ of the cases the revision is more than $2 \%$.

Figures 4 and 5 report the frequency distribution of the largest quarterly revision reported for each of the 238 MSAs. From this perspective, the revisions to the estimate of housing prices are considerably larger. As can be seen from Fig. 4, the largest revision in the house price index averages almost 3\% in any MSA. In fully $14.7 \%$ of the MSAs, that is, in 35 out of $238 \mathrm{MSAs}$, the largest revision exceeds $6 \%$-during an interval of 6 years.

Figure 5 reports the frequency distribution of the largest revision, in absolute terms, across the $238 \mathrm{MSAs}$. This distribution is much larger. On average, the largest revision is more than $4.6 \%$. In $32 \%$ of the regions, the largest absolute revision is more than $5 \%$. In $8.7 \%$ (i.e., in 21 out of 238) of the MSAs, the largest absolute revision exceeds $7.5 \%$.

On average, the revisions to the price indexes in these 238 MSAs are small. The largest revisions in the estimates of housing prices between 2001 and 2007 are quite large, however, for about one fourth of the MSAs. 


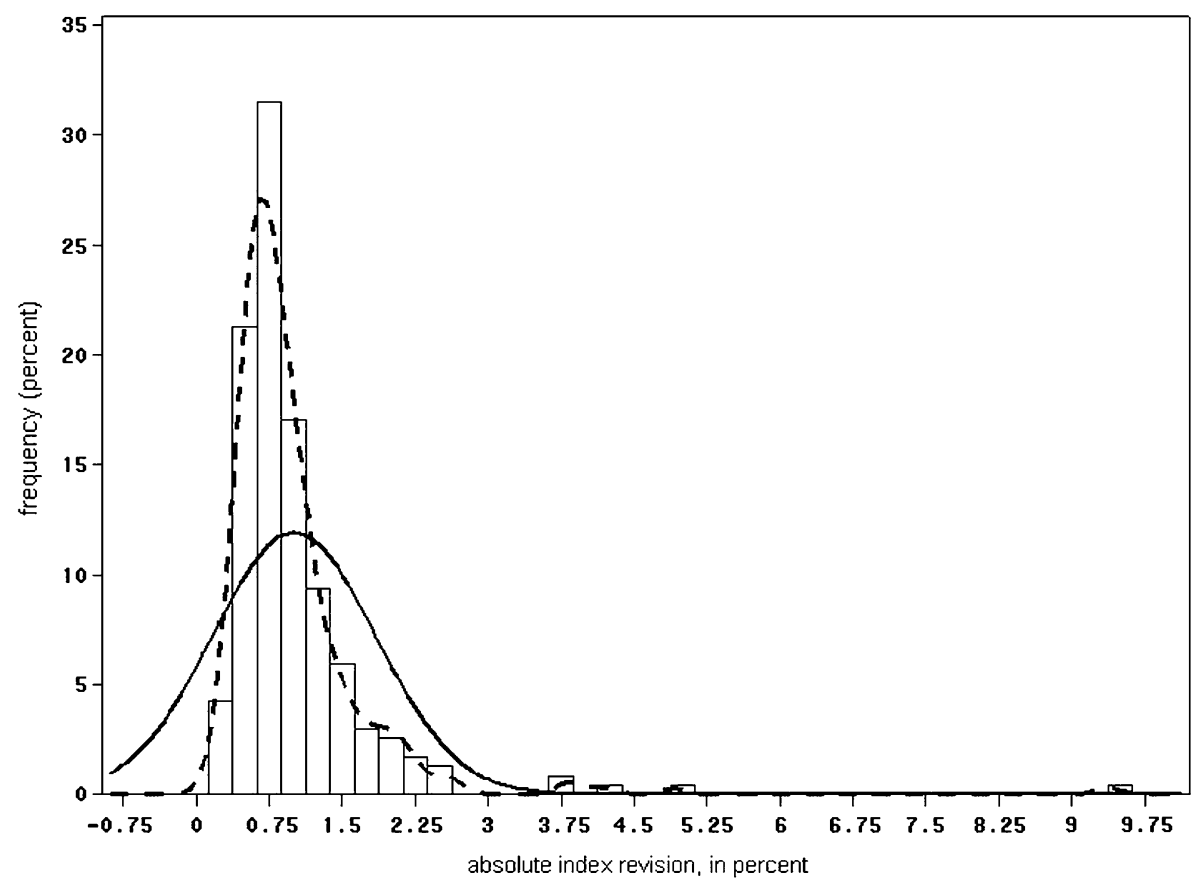

Fig. 3 Frequency distribution of mean absolute quarterly revision in house price index, in percent 2007Q1 versus 2001Q1 (238 MSAs)

The Temporal Patterns of Revisions

Figures 2, 3, 4 and 5 report each MSA as one point in the frequency distributions of average revisions across metropolitan areas. But of course, revisions are reported for each MSA for each quarter from 1975Q1 through 2001Q1. Figure 6 reports the revisions for all available time periods for nine metropolitan areas which have the largest revisions in absolute size. Figure 7 reports the pattern of revisions for ten more representative metropolitan areas, ones for which the average absolute revisions are about average.

In general, the qualitative pattern of revisions is similar in the figures. The absolute magnitude of the revisions is much larger for index values reported in the recent past, say from 1996 onwards, than it is for those reported for the more distant past. Note that for the MSAs with large revisions, in Fig. 6, the changes in the index numbers in the recent past can be quite large. The pattern of revisions for the sample of other MSA is similar, but the ordinate in the figure is very different. The volatility of revisions to index values reported for the recent past relative to the more distant past undoubtedly reflects the fact that more paired sales from the previous 5 to 10 years are added to each sample during the interval between 2001 and 2007. These recent paired sales clearly have a larger effect upon the estimated index values during the period. 


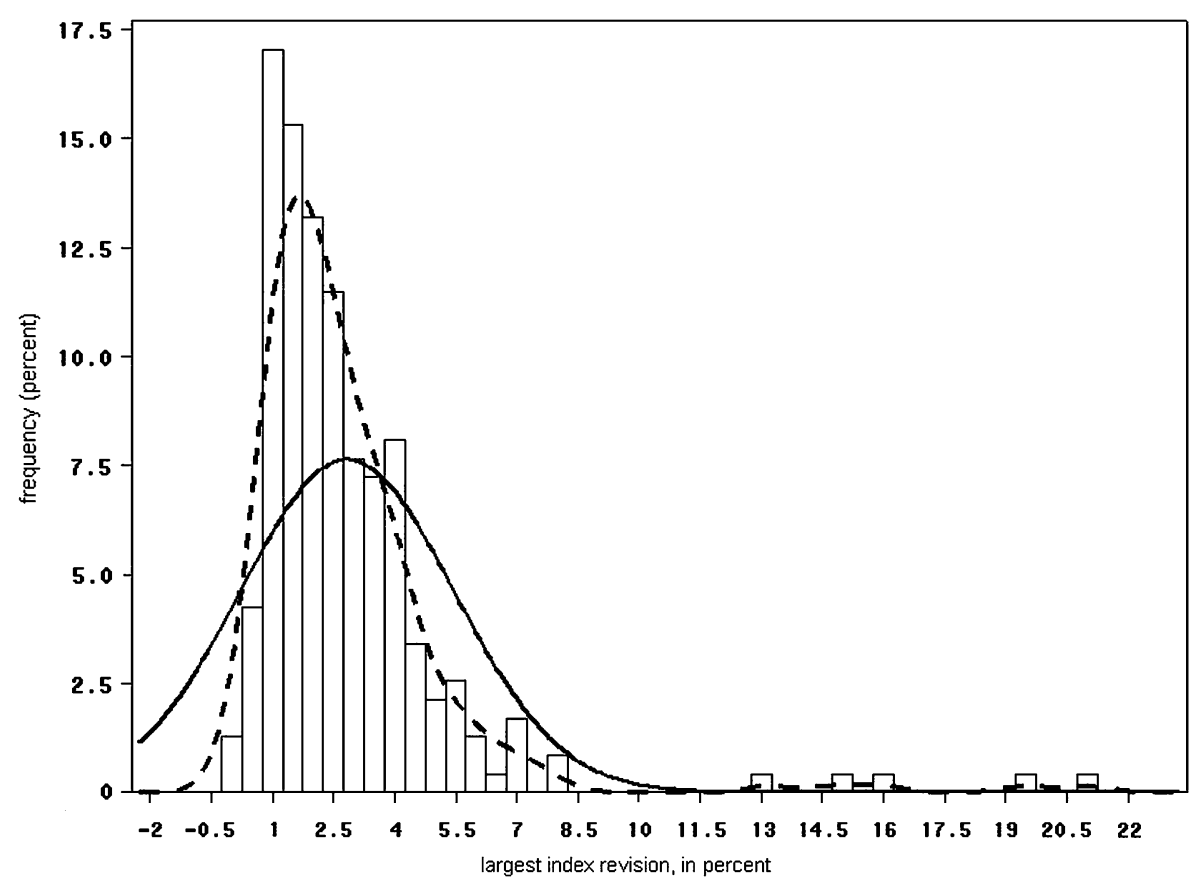

Fig. 4 Frequency distribution of largest quarterly revision in house price index, in percent 2007Q1 versus 2001Q1 (238 MSAs)

The Predictability of Price Index Revisions

As we have seen, the magnitudes of revisions are small, on average, but they are larger when their absolute size is considered. Larger revisions and more volatility are concentrated in the most recent 5- to 10-year period for most MSAs. In this section, we investigate the predictability of these revisions. We investigate the pattern of serial correlation in the index revisions and the systematic effects across real time and housing market.

The basic autocorrelation model investigated is

$$
\log \left(\widetilde{P}_{i t} / P_{i t}\right)=\log \left[R_{t}\right]=\beta_{0}+\sum_{j=1}^{4} \beta_{j} \log P_{i, t-j}+\sum_{k=1}^{T} \delta_{k} d_{i k}+\sum_{n=1}^{N} \gamma_{n} I_{i n}
$$

In this formulation, $\widetilde{P}_{i t}$ is the price index for metropolitan area $i$ for time $t$ as revised in 2007Q1, and $P_{i t}$ is the price index as published in 2001Q1, 6 years before. $R_{i t}$ is the percent revision in the house price between 2001 and 2007 for quarter $t$ in MSA $i, d_{k}$ is a quarterly dummy variable measuring the temporal fixed effect $(k=1$, $2, \ldots, T)$, and $I_{n}$ is an MSA dummy variable measuring the fixed housing market effect $(n=1,2, \ldots, N)$. The model is estimated using a four-quarter lag on the initial index value together with a set of temporal and/or geographic fixed effects. 


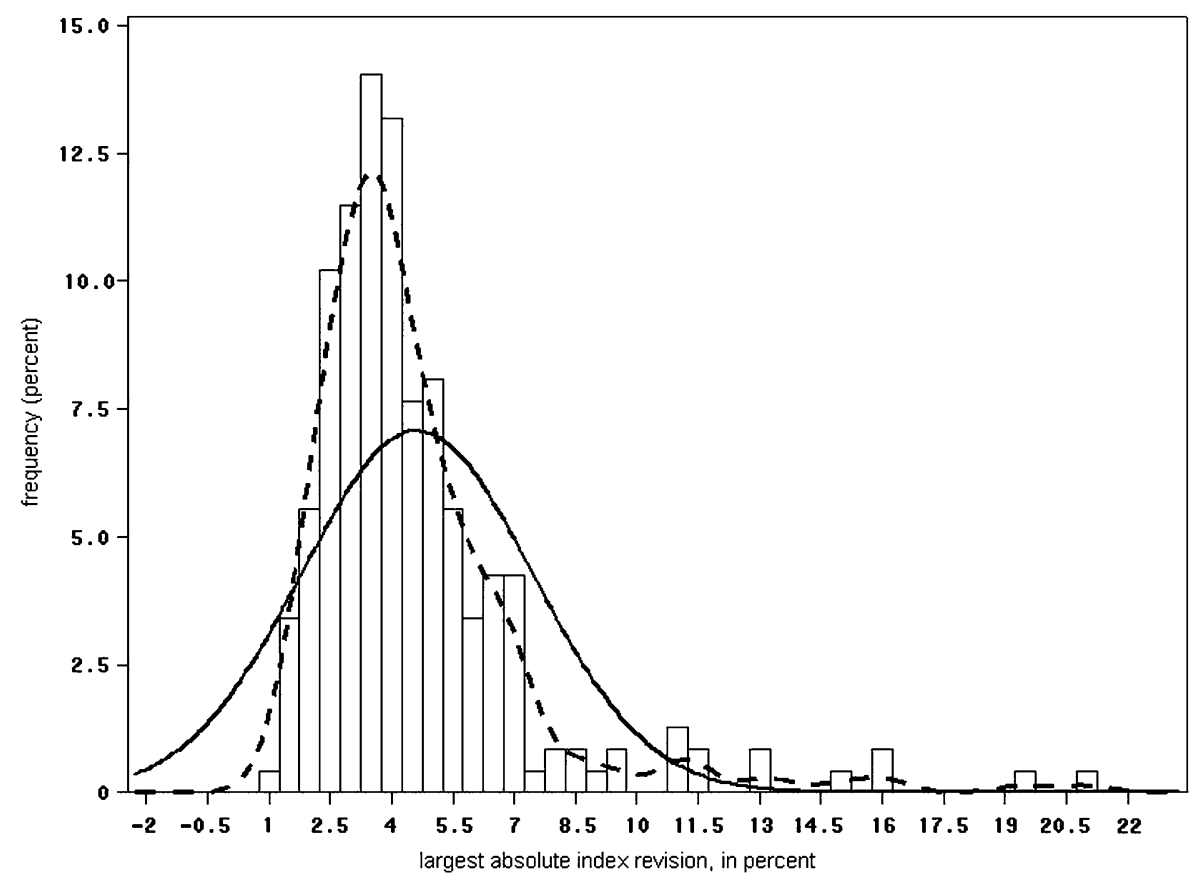

Fig. 5 Frequency distribution of largest absolute quarterly revision in house prices, in percent 2007Q1 versus 2001Q1 (238 MSAs)

Figure 8 summarizes the results of estimating this equation separately for each of the 238 MSAs. It presents the frequency distribution of the variance in revision that is explained by the simple lag structure. As shown in the figure, the modal estimates of $R^{2}$ are about $10 \%$ and $30 \%$. The mean of the distribution is about $28 \%$. This

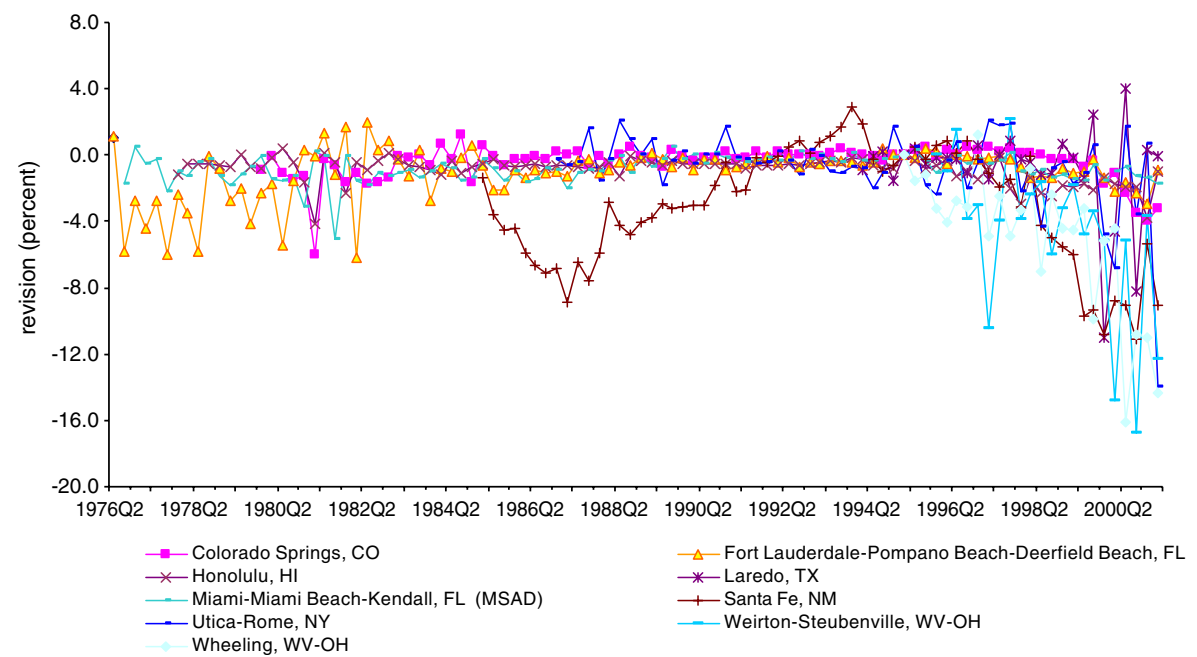

Fig. 6 House price index revisions, 1975Q1 through 2001Q1 for selected MSAs with the largest revisions 2007Q1 versus 2001Q1

Springer 


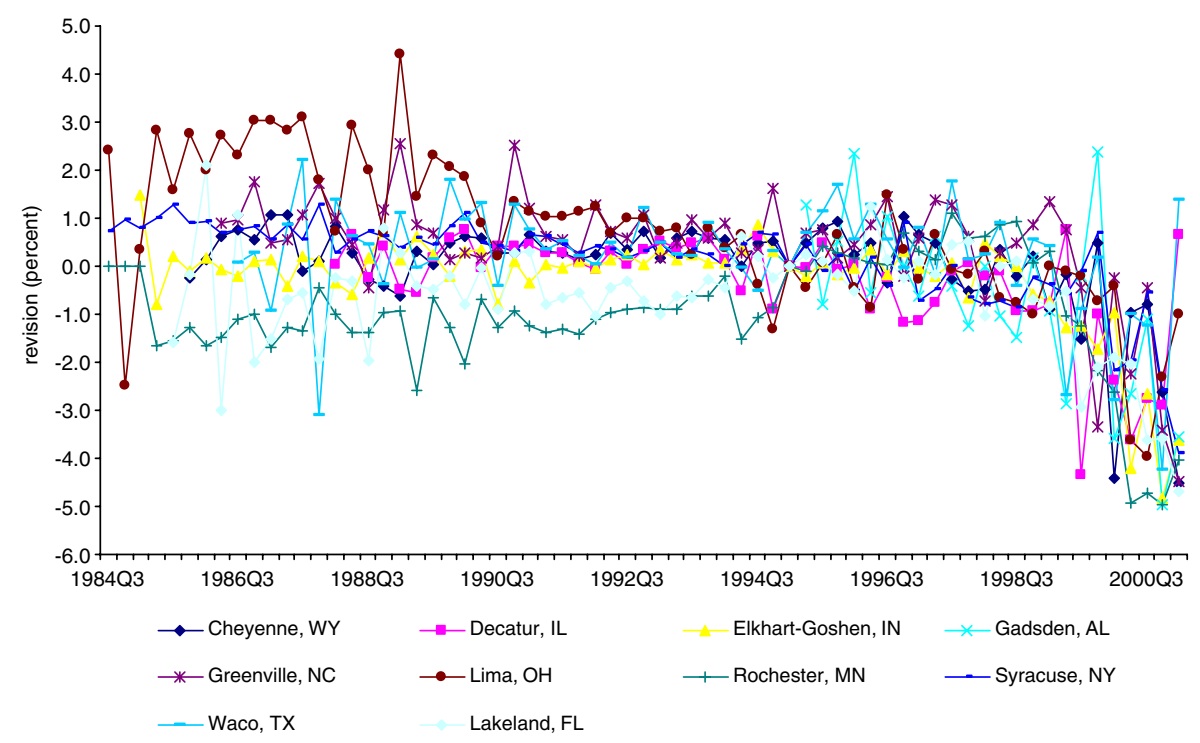

Fig. 7 House price index revisions, 1975Q1 through 2001Q1 for selected MSAs with the average revisions in absolute terms 2007Q1 versus 2001Q1

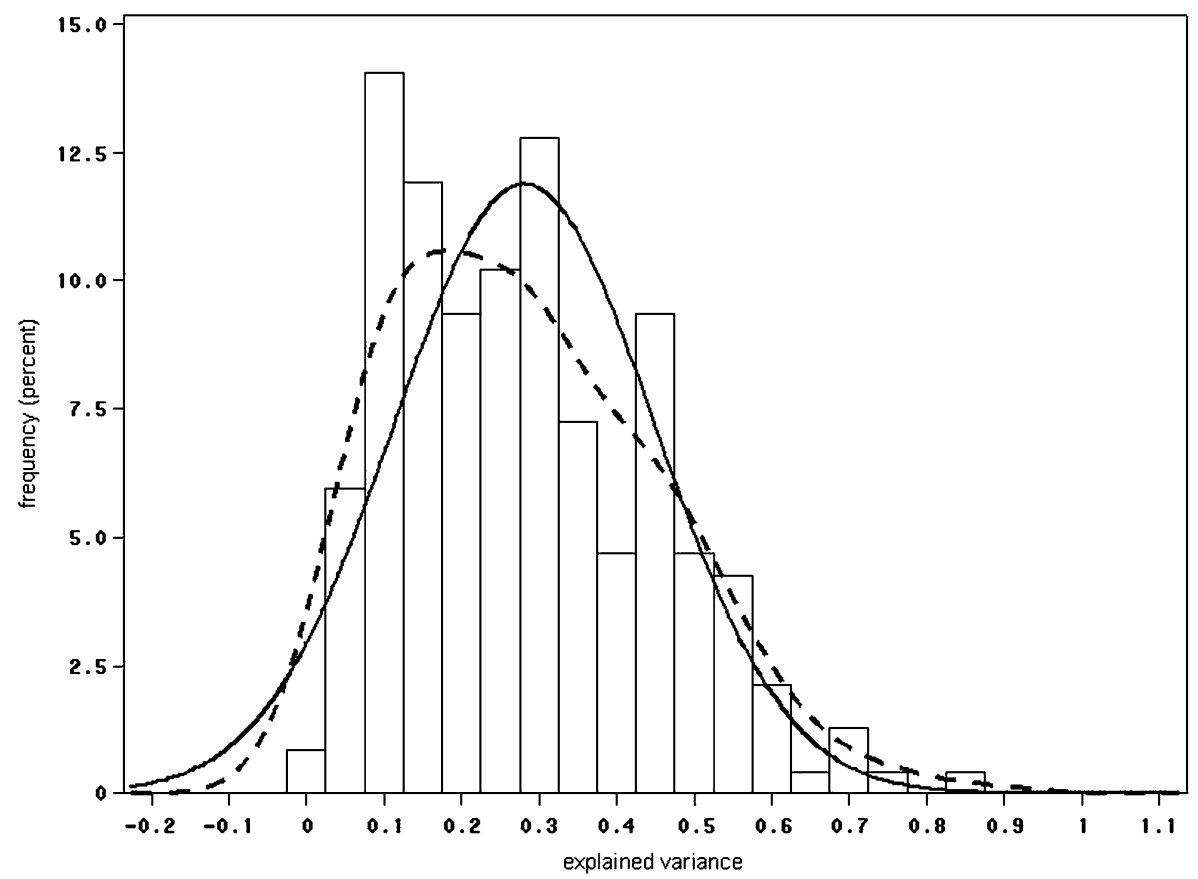

Fig. 8 Frequency distribution of explained variance $\left(R^{2}\right)$ of price revision regressions (Eq. 5) estimated separately for each MSA (238 MSAs) 
Table 2 Estimates of price revision regressions (Eq. 5; pooled across $238 \mathrm{MSAs}$ )

Model I is estimated with 85 quarterly fixed time effects (1980Q1-2001Q1). Model II is estimated with 237 MSA fixed effects, and model III is estimated with both fixed time effects and MSA fixed effects

\begin{tabular}{lccc}
\hline & I & II & III \\
\hline Intercept & 0.0169 & 0.0351 & 0.0037 \\
& $(3.18)$ & $(13.38)$ & $(0.75)$ \\
$\log P_{i, t-1}$ & 0.0004 & -0.0223 & 0.0053 \\
& $(0.10)$ & $(-5.75)$ & $(1.44)$ \\
$\log P_{i, t-2}$ & 0.0123 & 0.0084 & 0.0115 \\
& $(2.21)$ & $(1.70)$ & $(2.51)$ \\
$\log P_{i, t-3}$ & -0.0178 & -0.0108 & -0.0186 \\
& $(-3.29)$ & $(-2.23)$ & $(-4.16)$ \\
$\log P_{i, t-4}$ & 0.0004 & 0.0142 & -0.0030 \\
& $(0.10)$ & $(3.81)$ & $(-0.84)$ \\
Fixed time effects & Yes & No & Yes \\
Fixed MSA effects & No & Yes & Yes \\
$\mathrm{R}^{2}$ & 0.165 & 0.316 & 0.439 \\
No. of observations & 14,913 & 14,913 & 14,913 \\
& & & \\
\hline
\end{tabular}

suggests that the recent price history in a metropolitan area, known at the time the initial index value is published, may explain up to about a third of the price revisions in a metropolitan housing market a half decade later.

Table 2 presents regression estimates of Eq. 5 pooled across metropolitan areas and time periods. Model I sets $\gamma$ equal to zero. In other words, the model includes the lagged price variables plus the fixed effects for each quarter. Model II sets $\delta$ equal to zero. The model includes the lagged price variables plus the fixed effects for each housing market. Model III includes both fixed effects for time periods and different housing markets. As indicated in the table, a simple model with fixed effects for each time period explains about $17 \%$ of the variance in the ratio of revisions. A simple model with fixed effects for each metropolitan housing market explains about $32 \%$ of the variance. When the model includes both fixed effects for time period and metropolitan housing market, it explains more than $44 \%$ of the variance in index revisions across the set of 238 markets.

Figure 9 reports the estimates of the fixed effects for time from Table 2 Model I. There are 85 quarterly fixed time effects from 1980Q1 through 2001Q1. ${ }^{7}$ Note that for most of the period, the price revision is very small. However, the estimated fixed effects for time increase modestly between 1982 and 1996 and decline systematically thereafter.

Figure 10 summarizes the fixed effects associated with different housing markets. They average about $1 \%$ in terms of the log revision ratio. Notice, however, there is a thick left tail around -0.02 to -0.03 , indicating a "downward" revision of more than $2 \%$ for some housing markets. Figure 11 summarizes the estimated log price revision based on Table 2 Model III. Over $40 \%$ of the 238 housing markets have estimated negative (downwards) price revision over the sampling period, and about $20 \%$ of the markets have estimated positive (upwards) price revision. The remaining markets have the price revision centered on zero (i.e., the upward and downward price revisions offset each other during the sampling period).

The importance of systematic time-varying factors is investigated in Table 3. In this analysis, the dependent variable is the vector of fixed-time effects graphed in

\footnotetext{
${ }^{7}$ Data prior to 1980 are too sparse to support estimation of the fixed time effects. 


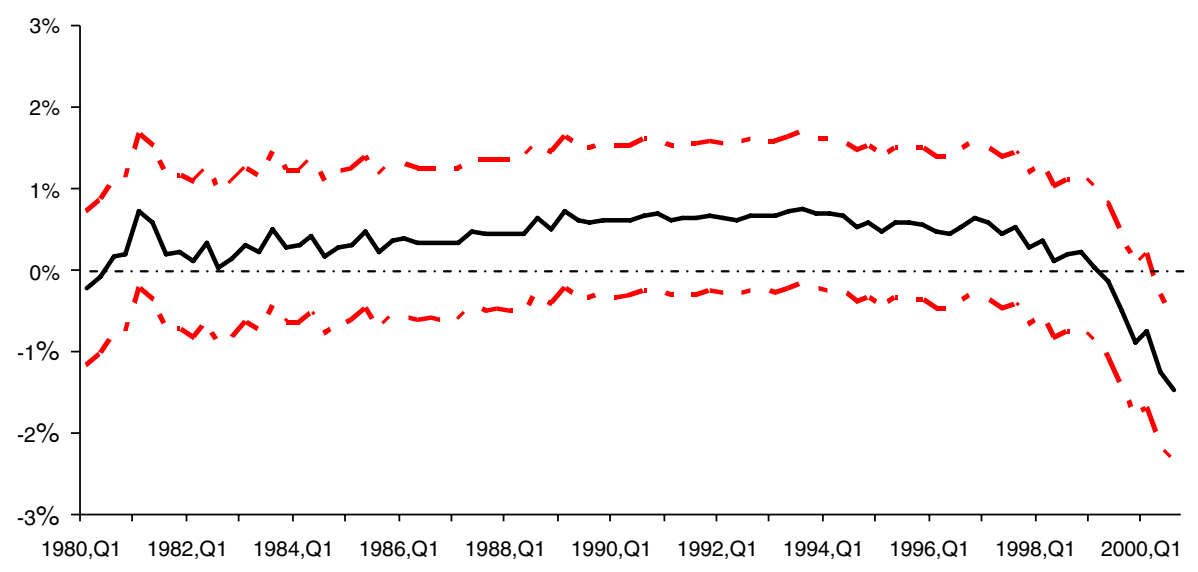

Fig. 9 Time-specific effects on price revisions, in percent with 95\% Confidence interval (based on Table 2 Model I)

Fig. 9. There are 85 estimates of quarterly fixed effects, from 1980Q1 through 2001Q1. Panel A reports the regression relationship between personal income and the temporal variation in revisions, as reported in Fig. 9. Panel B reports the regression relationship between interest rates and the fixed time effects. Panel $\mathrm{C}$ reports the relationship between the slope of the yield curve (i.e., the spread between

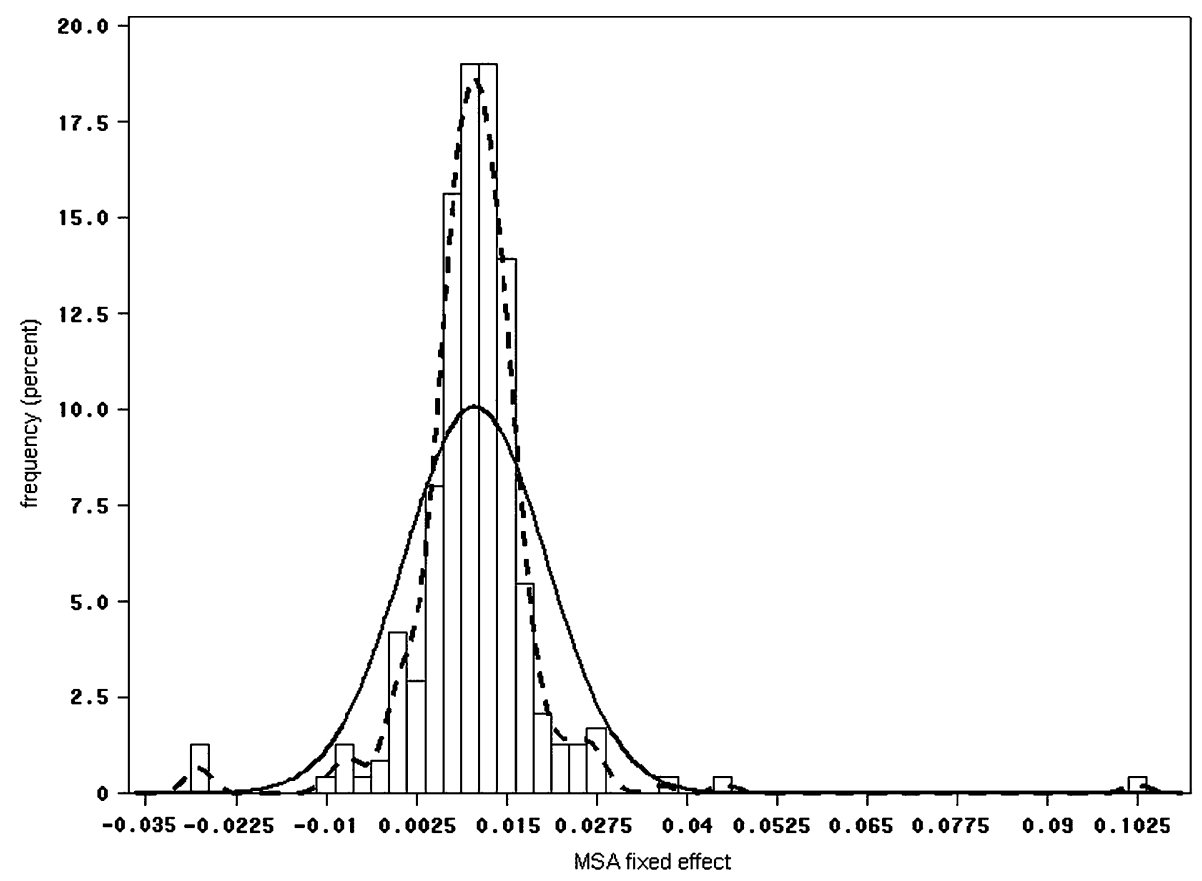

Fig. 10 Frequency distribution of MSA fixed effects estimated from the log price revision ratio regression (based on Table 2 Model II) 


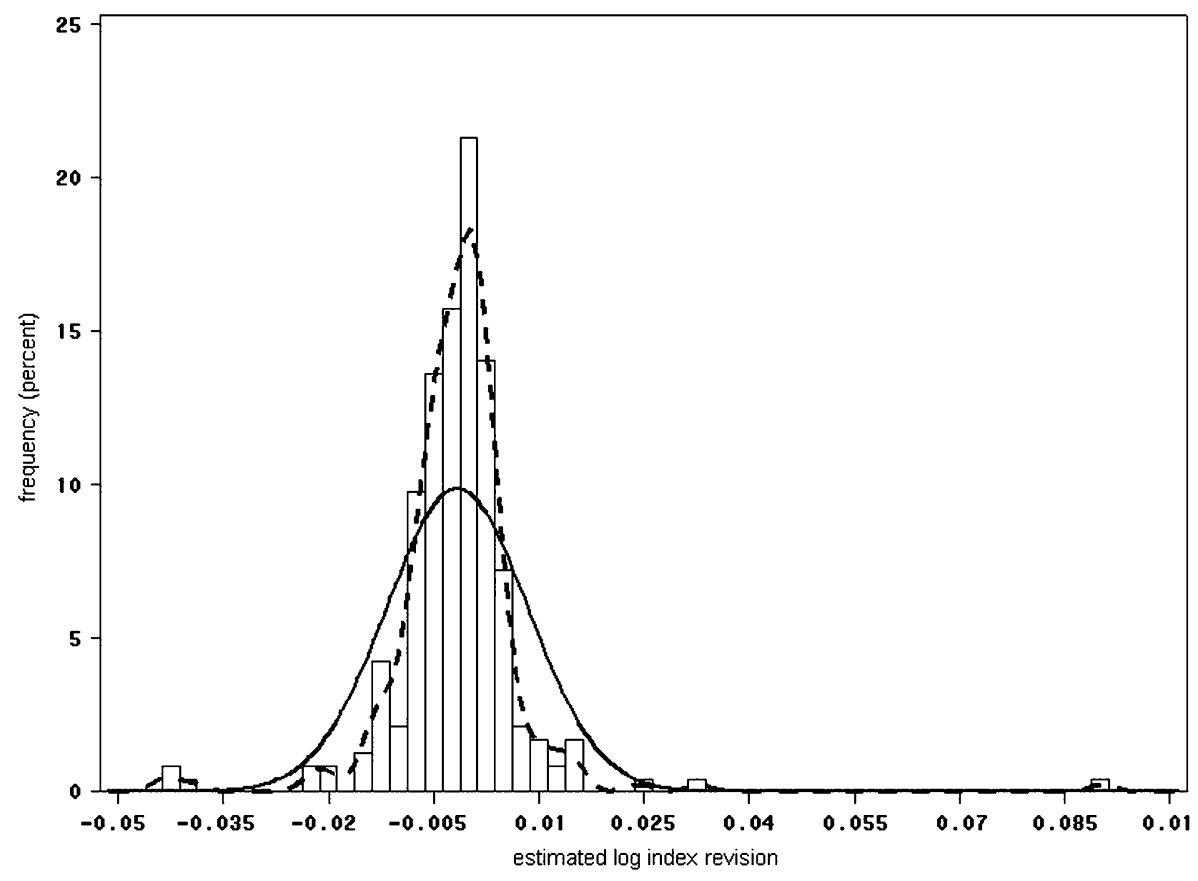

Fig. 11 Frequency distribution of estimated log price revision ratios for 238 MSAs (based on Table 2. Model III)

10-year and 1-year Treasury securities) and the revisions. For each of the three models, we report results using one, two and three-quarter lags.

There is essentially no evidence that the course of interest rates or a distributed lag of income systematically affects the revisions to the house price indexes. The explained variance in each of the regressions is small, and few of the coefficients are significant by conventional criteria. There is somewhat more evidence that the slope of the yield curve affect the time pattern of revisions to house price indexes. The explained variance is small, about $4-17 \%$, but the regressions do suggest that the revisions vary with current slope of yield curve.

\section{Conclusions}

A functioning market for house price derivatives would enable homeowners to hedge their unbalanced portfolios of debt and equity instruments. A viable market in these derivatives is predicated on transparent and replicable indexes of regional housing prices over time. In many OECD countries, these price estimates would necessarily be based upon some form of a repeat-sales price index. Inherent in the choice of this measure is some extent of revision after indexes are initially published.

The small house price derivatives market currently operating in the USA is based upon only ten metropolitan housing markets, and settlement is based on proprietary 
Table 3 Macroeconomic determinants of fixed time effects

\begin{tabular}{|c|c|c|c|c|}
\hline & I & II & III & IV \\
\hline \multicolumn{5}{|c|}{ Log income $I^{\mathrm{a}}$} \\
\hline$I_{t}$ & $\begin{array}{l}-0.0058 \\
(-1.87)\end{array}$ & $\begin{array}{l}-0.2113 \\
(-1.46)\end{array}$ & $\begin{array}{l}-0.2402 \\
(-1.67)\end{array}$ & $\begin{array}{l}-0.1781 \\
(-1.22)\end{array}$ \\
\hline$I_{t-1}$ & & $\begin{array}{c}0.2030 \\
(1.42)\end{array}$ & $\begin{array}{l}0.0121 \\
(0.06)\end{array}$ & $\begin{array}{l}-0.0658 \\
(-0.31)\end{array}$ \\
\hline$I_{t-2}$ & & & $\begin{array}{c}0.2169 \\
(1.54)\end{array}$ & $\begin{array}{c}0.0056 \\
(0.03)\end{array}$ \\
\hline$I_{t-3}$ & & & & $\begin{array}{l}0.2253 \\
(1.59)\end{array}$ \\
\hline Intercept & $\begin{array}{l}0.0266 \\
(2.31)\end{array}$ & $\begin{array}{l}0.0371 \\
(2.98)\end{array}$ & $\begin{array}{l}0.0496 \\
(3.72)\end{array}$ & $\begin{array}{c}0.0577 \\
(4.16)\end{array}$ \\
\hline $\begin{array}{l}F \text { value } \\
R^{2}\end{array}$ & $\begin{array}{l}3.478 \\
0.040\end{array}$ & $\begin{array}{l}3.423 \\
0.078\end{array}$ & $\begin{array}{l}3.893 \\
0.129\end{array}$ & $\begin{array}{l}3.864 \\
0.167\end{array}$ \\
\hline \multicolumn{5}{|c|}{ Interest rate $R$} \\
\hline$R_{t}$ & $\begin{array}{l}-0.0175 \\
(-0.96)\end{array}$ & $\begin{array}{l}0.0133 \\
(0.23)\end{array}$ & $\begin{array}{l}-0.0058 \\
(-0.08)\end{array}$ & $\begin{array}{l}-0.0128 \\
(-0.19)\end{array}$ \\
\hline$R_{t-1}$ & & $\begin{array}{l}-0.0271 \\
(-0.48)\end{array}$ & $\begin{array}{l}0.0095 \\
(0.10)\end{array}$ & $\begin{array}{c}0.0169 \\
(0.16)\end{array}$ \\
\hline$R_{t-2}$ & & & $\begin{array}{l}-0.0160 \\
(-0.28)\end{array}$ & $\begin{array}{l}-0.0426 \\
(-0.43)\end{array}$ \\
\hline$R_{t-3}$ & & & & $\begin{array}{c}0.0277 \\
(0.46)\end{array}$ \\
\hline Intercept & $\begin{array}{l}0.0064 \\
(4.74)\end{array}$ & $\begin{array}{l}0.0062 \\
(4.46)\end{array}$ & $\begin{array}{l}0.0061 \\
(4.31)\end{array}$ & $\begin{array}{l}0.0060 \\
(4.13)\end{array}$ \\
\hline$F$ value & 0.919 & 0.354 & 0.147 & 0.132 \\
\hline$R^{2}$ & 0.011 & 0.009 & 0.006 & 0.007 \\
\hline \multicolumn{5}{|c|}{ Slope of yield curve $S^{\text {a }}$} \\
\hline$S_{t}$ & $\begin{array}{l}0.8690 \\
(4.10)\end{array}$ & $\begin{array}{l}0.3715 \\
(0.53)\end{array}$ & $\begin{array}{l}0.6229 \\
(0.77)\end{array}$ & $\begin{array}{l}0.6433 \\
(0.78)\end{array}$ \\
\hline$S_{t-1}$ & & $\begin{array}{l}0.4953 \\
(0.71)\end{array}$ & $\begin{array}{l}-0.1520 \\
(-0.11)\end{array}$ & $\begin{array}{l}-0.0637 \\
(-0.05)\end{array}$ \\
\hline$S_{t-2}$ & & & $\begin{array}{l}0.4096 \\
(0.51)\end{array}$ & $\begin{array}{c}0.0874 \\
(0.06)\end{array}$ \\
\hline$S_{t-3}$ & & & & $\begin{array}{l}0.2264 \\
(0.27)\end{array}$ \\
\hline Intercept & $\begin{array}{l}-0.0052 \\
(-2.01)\end{array}$ & $\begin{array}{l}-0.0051 \\
(-1.93)\end{array}$ & $\begin{array}{l}-0.0052 \\
(-1.89)\end{array}$ & $\begin{array}{l}-0.0054 \\
(-1.86)\end{array}$ \\
\hline$F$ value & 16.784 & 7.940 & 5.050 & 3.661 \\
\hline$R^{2}$ & 0.168 & 0.164 & 0.161 & 0.160 \\
\hline
\end{tabular}

price indexes whose properties are not publicly disclosed. Moreover, no information is available about the incidence of index revision as new information becomes available.

Under current trading rules, contracts are settled using index values current at the settlement date, and it is hard to see how an alternative settlement procedure is viable. If, however, subsequent revisions to the price index in a given market at a specific date were large, or if they were systematic, the integrity of the derivatives market would be threatened. No information is available at all about the magnitude of revisions to these indexes.

Alternatively, contract settlement could be based upon the OFHEO indexes, published quarterly by a US government agency and widely available for all US metropolitan areas. Our empirical analysis provides the first systematic evidence of 
the extent of these revisions. We consider the properties of indexes published in 2001 and 2007, after an interval of 6 years.

First, we find that over this relatively short interval the geographical definitions of metropolitan areas are subject to substantial revision. Of the 329 MSAs for which price indexes were published in 2001, only 238 had the same geographical boundaries in 2007. This means that if the OFHEO indexes were to be used for settling futures contracts in the USA, the agency would need to publish a full set of historical indexes continuously. This would mean publishing price indexes in each quarter for all current MSAs and for all MSAs which have been defined over some reasonable period of time.

This is not an insurmountable obstacle, but it would require the agency to preserve geographical identifiers for each sale in its data base (say, the latitude and longitude of each transaction), and to produce current price index estimates for all geographical configurations of MSAs which have been used in the past. With the passage of time, this could become quite cumbersome, and this would probably limit the trading in house price derivatives to a short period, say, contracts of 5 to 8 years.

For those metropolitan areas whose geography remained fixed during the 20012007 period, our analysis provides an extensive comparison and quantification of index revisions. The average quarterly revision across these 238 MSAs is not at all large, about $-0.125 \%$ in any MSA. However, in about one quarter of the MSAs, the average revision is about $1.5 \%$ in absolute size, and in about $15 \%$ of the housing markets, the average absolute revision exceeds $2 \%$. The largest revision in a metropolitan housing market is sometimes quite large indeed.

The largest revisions in any MSA are concentrated in the index numbers reported in the recent past - say during 1996-2001-for indexes reported in 2001 and revised in 2007. This is to be expected, because updating the repeat sales index typically adds many more observations on paired sales for the recent past. These magnitudes are rather large, and when coupled with the likelihood that futures will be traded for no more than 5 to 8 years, this may make trade in index-based options much less attractive.

On the other hand, there is little evidence that the revisions to these indexes are strongly predictable, either on the basis of lags and serial correlation or on the basis of simple macroeconomic factors. Our analysis suggests that the property of index revision makes the settlement of futures contracts less precise, but not subject to systematic biases. Nevertheless, our analysis - especially the magnitude of the arbitrary revisions to price estimates - suggests a limitation in the efficiency gains from trading in housing price futures.

\section{References}

Abraham, J. M., \& Schauman, W. S. (1991). New evidence on home prices from Freddie Mac repeat sales. AREUEA Journal 19(3):333-352.

Bailey, M. J., Muth, R. F., \& Nourse, H. O. (1963). A regression method for real estate price index construction. Journal of the American Statistical Association 58(304):933-942.

Butler, J. S., Chang, Y., \& Cutts, A. C. (2005). Revision bias in repeat-sales home price indices. Freddie Mac working paper \#05-03. 
Calhoun, C. A. (1996). OFHEO house price indexes: HPI technical description," working paper. Washington, DC: Office of Federal Housing Enterprise Oversight (OFHEO).

Case, K. E., \& Shiller, R. J. (1989). The efficiency of the market for single family homes. American Economic Review 79(1):125-137.

Case, K. E., Shiller, R. J., \& Weiss, A. N. (1993). Index-based futures and options markets in real estate. Journal of Portfolio Management 19(2):83-92.

Clapp, J. M., \& Giaccotto, C. (1999). Revisions in repeat-sales price indexes: Here today, gone tomorrow? Real Estate Economics 27(1):79-104.

Clapham, E., Englund, P., Quigley, J. M., \& Redfearn, C. L. (2006). Revisiting the past and settling the score: Index revision for house price derivatives. Real Estate Economics 34(2):275-302.

CME (2007a). CME housing future and options: Opening up new opportunities. Chicago Mercantile Exchange, Chicago, IL.

CME (2007b). CME housing futures and options: Frequently asked questions. Chicago Mercantile Exchange, Chicago, IL.

Englund, P. (2003). Taxing residential housing capital. Urban Studies 40:937-952.

Englund, P., Hwang, M., \& Quigley, J. M. (2002). Hedging housing risk. Journal of Real Estate Finance Economics 24(1/2):167-200.

Goetzmann, W. N., et al. (2003). Home equity insurance: A pilot project. Yale ICF working paper \#03-12. Iacoviello, M., \& Ortalo-Magné, F. (2003). Hedging housing risk in London. Journal of Real Estate Finance Economics 27(2):191-209.

Quigley, J. M. (2006). Real estate portfolio allocation: The European consumers' perspective. Journal of Housing Economics 15:169-188. 